\section{BMJ Open} Ophthalmology

\title{
Role of ethnicity and socioeconomic status (SES) in the presentation of retinoblastoma: findlings from the UK
}

\author{
Rabia Bourkiza (D) , ${ }^{1}$ Phillippa Cumberland, ${ }^{2}$ Ido Didi Fabian, ${ }^{1,3,4}$ \\ Hiranya Abeysekera, ${ }^{5}$ Manoj Parulekar, ${ }^{5}$ Mandeep S Sagoo, ${ }^{1,4,6}$ Jugnoo Rahi, ${ }^{2,4,7}$ \\ M Ashwin Reddy ${ }^{1,4,6}$
}

To cite: Bourkiza $\mathrm{R}$ Cumberland P, Fabian ID, et al. Role of ethnicity and socioeconomic status (SES) in the presentation of retinoblastoma: findings from the UK. BMJ Open Ophthalmology 2020;5:e000415. doi:10.1136/ bmjophth-2019-000415

Received 4 December 2019 Revised 11 March 2020 Accepted 27 April 2020
Check for updates

(c) Author(s) (or their employer(s)) 2020. Re-use permitted under CC BY-NC. No commercial re-use. See rights and permissions. Published by BMJ.

For numbered affiliations see end of article.

Correspondence to Dr Rabia Bourkiza; r.bourkiza@ nhs.net

\section{ABSTRACT}

Background The relationship between the ethnic background or socioeconomic status (SES) and late retinoblastoma $(\mathrm{Rb})$ presentation in the UK is unclear. We aimed to investigate if such correlations exist in a cohort of non-familial $\mathrm{Rb}$ cases.

Methods A cross-sectional study based at the two centres providing $\mathrm{Rb}$ care in the UK. Included were non-familial $\mathrm{Rb}$ cases that presented from January 2006 to December 2011. Epidemiological and clinical data were retrieved from medical charts, as well as patients' postcodes used to obtain the Index of Multiple Deprivation (IMD) score. A postal questionnaire was sent to participants' parents to collect further, personlevel, information on languages spoken and household socioeconomic position. Statistical correlations to advanced $\mathrm{Rb}$ at presentation as well as to treatment by enucleation and need for adjuvant chemotherapy were investigated.

Results The cohort included 189 cases, 98 (51.8\%) of which were males. The median age at diagnosis was 16 months (IQR 8-34 months). Of the study patients, $153(81 \%)$ presented with advanced Rb; 78 (41\%) with group D and 75 (40\%) with group E Rb. A total of 134 $(72 \%)$ patients were treated with enucleation. South Asian ethnicity and being in the most deprived IMD quintile were associated with a higher likelihood of presentation with advanced disease, but these estimates did not reach statistical significance. Older age at presentation was associated with enucleation and bilateral disease with adjuvant chemotherapy.

Conclusions In this national UK study of patients with non-familial $\mathrm{Rb}$, there was no evidence of an association of ethnicity or SES and the risk of presenting with advanced disease. These findings may reflect equality in access of healthcare in the UK.

\section{INTRODUCTION}

Retinoblastoma $(\mathrm{Rb})$ is the most common primary intraocular malignancy of childhood worldwide, ${ }^{1}$ with approximately 50-60 new cases per year in the UK.

The International Intraocular Retinoblastoma Classification (IIRC) describes five groups of $\mathrm{Rb}(\mathrm{A}-\mathrm{E}),{ }^{2}$ which represent the continuum of intraocular disease progression.

\section{Key messages}

What is already known about this subject?

- In the USA it was suggested that Hispanics and those from unfavourable socioeconomic background have more advanced retinoblastoma at presentation.

- In Mexico and Brazil, maternal education was found to be predictive of outcome of retinoblastoma.

What are the new findings?

- In this national UK study, we found no association between advanced retinoblastoma and ethnicity or socioeconomic factors.

How might these results change the focus of research or clinical practice?

- Our findings reflect the equality in access to primary healthcare in the UK. There are existing awareness campaigns highlighting the white reflex and strabismus and these should continue in their current format.

While globe salvage with focal treatments and/or chemotherapy occurs in more than $90 \%$ for groups $\mathrm{A}-\mathrm{C},{ }^{3}$ the figure is just over $60 \%$ for group D eyes, ${ }^{4}$ and group $\mathrm{E}$ eyes (the most advanced form) are often enucleated at presentation. Rb surgeons often elect to primarily enucleate group E eyes as $39 \%$ of cases require adjuvant chemotherapy to reduce the risk of metastases. ${ }^{5}{ }^{6}$ Thus, early diagnosis and prompt treatment is crucial for globe salvage, reduced morbidity and possibly preservation of vision.

It is recognised that in resource poor countries increased lag time (time to diagnosis interval) is associated with increased mortality and extraocular $\mathrm{Rb}^{78}$ Recently, it has been demonstrated in the UK that increased lag time for children with $\mathrm{Rb}$ is not associated with an increased risk of adjuvant chemotherapy after enucleation nor higher frequency of group E eyes. ${ }^{9}$

Similarly, low socioeconomic status (SES) has been stated as an important factor in 
the development of advanced disease in resource poor countries. ${ }^{10}$ In the USA, one study reported a trend for Hispanic children and children with no healthcare insurance to have more advanced disease although statistical significance was not achieved. ${ }^{11}$

In the UK, the National Health Service (NHS) aims to provide equal access to healthcare. We were keen to understand which ethnic or socioeconomic groups, if any, were presenting with advanced $\mathrm{Rb}$ leading to adverse outcomes, including mortality, enucleation and adjuvant chemotherapy. Identification of specific groups would enable resources to be directed to these groups.

\section{METHODS}

\section{Study population and data collection}

This was a national multicentre, retrospective, noncomparative study evaluating non-familial $\mathrm{Rb}$ cases in the UK.

Two centres in London and Birmingham provide the national $\mathrm{Rb}$ service to the UK population in which all affected children are diagnosed and treated. The registries at these two centres, the Royal London Hospital, Barts Health NHS Trust and Birmingham Children's Hospital, were reviewed and non-familial cases of $\mathrm{Rb}$ presenting between 1 January 2006 and 31 December 2011 were identified. Only non-familial cases were included in this study as screening is already available for first-degree relatives of patients with $\mathrm{Rb}$. As such presentation of familial $\mathrm{Rb}$ is not initiated by these families. This research adhered to the tenets of the Declaration of Helsinki. Written parental consent was obtained for inclusion of participants in the questionnaire part of the study. Patients or the public were not involved in the design, or conduct, or reporting, or dissemination plans of our research. The Childhood Eye Cancer Trust is interested in the findings of this paper and is dedicated to increasing awareness of $\mathrm{Rb}$.

Data collected on all patients from electronic patient records included: age at diagnosis (months), sex, child's ethnicity, IIRC stage at diagnosis, ${ }^{2}$ bilaterality, treatment and postcodes. In cases of bilateral disease, the stage of the worse eye was recorded. Individual postcode (ZIP code) data were used to obtain the Index of Multiple Deprivation (IMD) score, a relative deprivation score based on residential location. IMD is the official measure of relative deprivation for small areas in the UK. It ranks every small area according to income, employment, health, education, housing, access and child poverty. Higher scores of IMD indicate higher SES. ${ }^{12}$

A postal questionnaire was also sent to participants' parents to collect further, person-level, information on languages spoken at home and household socioeconomic position, including housing tenure, main carer's educational qualifications and main wage earner's employment status and occupation coded using the Standard Occupational Classification from the UK Office of National Statistics. ${ }^{13}$ This was not a validated questionnaire.
Parents were contacted twice by mail and at least twice by telephone if they did not respond, to maximise completion and return of the questionnaire.

\section{Outcome measures}

Measures of severity of $\mathrm{Rb}$ included: IIRC stage (A-E) at diagnosis with groups $\mathrm{D}$ and $\mathrm{E}$ being considered advanced; requirement for primary enucleation; the use of adjuvant chemotherapy dependent on presence of high-risk features for systemic spread on histopathological evaluation (ie, massive choroidal invasion $(>3 \mathrm{~mm}$ ), retrolaminar optic nerve invasion or scleral invasion) $)^{14}$; and mortality.

\section{Statistical methods}

All calculations were performed using Microsoft Excel 2013 (Microsoft, Redmond, WA) and SPSS software V.17.0 (SPSS). $\chi^{2}$ test was used to investigate possible associations between clinical parameters and severity of $\mathrm{Rb}$ (IIRC groups A-C vs D/E), enucleation and adjuvant chemotherapy, and OR were calculated. For ethnicity, calculations were performed as English/Scottish/Welsh versus the various other categories (see table 1 ).

\section{RESULTS}

\section{Study sample characteristics}

A total of 192 children with sporadic non-familial $\mathrm{Rb}$ presented in the UK over the 6-year period of the study. Three cases were excluded from analysis. Two were due to incomplete data as they emigrated, and one declined consent. No child died during the study period, and no child died within 5 years from diagnosis. Thus, 189 cases were available for the present study with 5-year follow-up: $98(52 \%)$ male and 91 (48\%) female (table 1). Median age at diagnosis was 16 months (IQR 8-34 months), range 1 month to 12 years and 2 months; $117(62 \%)$ of cases presented in the first 2 years of life. There were 59 bilateral and 130 unilateral cases (67 right eye and 63 left eye). Left eyes were the worst affected eye in bilateral cases, compared with right eyes (47\% left eye vs $32 \%$ right eye); this difference was not statistically significant.

Overall, 153/189 (81\%) of non-familial $\mathrm{Rb}$ cases presented with advanced $\mathrm{Rb}$ (IIRC groups $\mathrm{D}$ and $\mathrm{E}$ ); 75 (40\%) group E, 78 (41\%) group D, 24 (13\%) group C, $11(6 \%)$ group B and 1 group A. The child with an IIRC A grade was detected by an optometrist on routine assessment. The majority, 134 (72\%), of cases were treated with enucleation, 124 (93\%) of whom had advanced disease. Those presenting with advanced $\mathrm{Rb}$ and those treated with enucleation were similarly distributed by demographic and socioeconomic factors to all cases (table 1), as were those receiving adjuvant chemotherapy $(68,50 \%$ of those that were enucleated).

Multivariable analysis showed children 2 years or older and those with bilateral $\mathrm{Rb}$ were more likely to present with advanced disease (table 2). Older age at presentation was associated with enucleation and bilateral disease with receipt of adjuvant chemotherapy. The relationship 
Table 1 Distribution of demographic and clinical factors for all cases $(n=189)$, by severity and treatment

\begin{tabular}{|c|c|c|c|c|c|c|c|c|}
\hline & \multicolumn{2}{|c|}{$\begin{array}{l}\text { Total } \\
\mathrm{n}=189 \\
\end{array}$} & \multicolumn{2}{|c|}{$\begin{array}{l}\text { Advanced IIRC } \\
\text { groups (D and E) } \\
n=153(81 \%)\end{array}$} & \multicolumn{2}{|c|}{$\begin{array}{l}\text { Enucleation } \\
\mathrm{n}=134(71 \%)\end{array}$} & \multicolumn{2}{|c|}{$\begin{array}{l}\text { Adjuvant } \\
\text { chemotherapy } \\
\mathrm{n}=68\end{array}$} \\
\hline & $n$ & $\%$ & $\mathrm{n}$ & $\%$ & $\mathrm{n}$ & $\%$ & $\mathrm{n}$ & $\%$ \\
\hline \multicolumn{9}{|l|}{ Gender } \\
\hline Female & 91 & 48.1 & 73 & 48 & 64 & 48 & 36 & 53 \\
\hline Male & 98 & 51.8 & 80 & 52 & 70 & 52 & 32 & 47 \\
\hline \multicolumn{9}{|l|}{ Ethnicity } \\
\hline English/Scottish/Welsh & 140 & 74 & 110 & 71.8 & 98 & 73.1 & 54 & 79.4 \\
\hline Non-English/Scottish/Welsh & 48 & 25.4 & 42 & 27.4 & 35 & 26.1 & 14 & 20.5 \\
\hline Indian/Pakistani/Bangladesh & 23 & 12.1 & 21 & 13.7 & 18 & 13.4 & 9 & 13.2 \\
\hline Black Caribbean/African & 8 & 4.2 & 6 & 3.9 & 4 & 2.9 & 1 & 1.4 \\
\hline Mixed white & 11 & 5.8 & 9 & 5.8 & 8 & 5.9 & 1 & 1.4 \\
\hline Other white & 3 & 1.5 & 3 & 1.9 & 3 & 2.2 & 1 & 1.4 \\
\hline Other & 3 & 1.5 & 3 & 1.9 & 2 & 1.4 & 2 & 2.9 \\
\hline Not known & 1 & 0.5 & 1 & 0.6 & 1 & 0.7 & 0 & 0 \\
\hline \multicolumn{9}{|l|}{ IMD score (quintiles) } \\
\hline 1 (most deprived) & 39 & 20.6 & 34 & 22.2 & 27 & 20.1 & 14 & 20.5 \\
\hline 2 & 44 & 23.2 & 35 & 22.8 & 32 & 23.8 & 17 & 25.0 \\
\hline 3 & 29 & 15.3 & 21 & 13.7 & 20 & 14.9 & 11 & 16.1 \\
\hline 4 & 33 & 17.4 & 28 & 18.3 & 25 & 18.6 & 12 & 17.6 \\
\hline 5 (least deprived) & 43 & 22.7 & 34 & 22.2 & 29 & 21.6 & 13 & 19.1 \\
\hline Not known & 1 & & 1 & & 1 & & & \\
\hline \multicolumn{9}{|l|}{ Age at diagnosis } \\
\hline$<1$ year & 71 & 37.5 & 52 & 33.9 & 41 & 30.5 & 27 & 39.7 \\
\hline 1 to $<2$ years & 46 & 24.3 & 35 & 22.8 & 31 & 23.1 & 16 & 23.5 \\
\hline 2 to $<3$ years & 32 & 16.9 & 29 & 18.9 & 28 & 20.8 & 10 & 14.7 \\
\hline 3 to $<4$ years & 27 & 14.2 & 24 & 15.6 & 21 & 15.6 & 10 & 14.7 \\
\hline 4 to 12 years & 13 & 6.8 & 13 & 8.4 & 13 & 9.2 & 5 & 7.3 \\
\hline \multicolumn{9}{|l|}{ Bilaterality } \\
\hline Unilateral & 130 & 68.7 & 103 & 67.3 & 97 & 72.3 & 35 & 51.4 \\
\hline Bilateral & 59 & 31.2 & 50 & 32.6 & 37 & 27.6 & 33 & 48.5 \\
\hline
\end{tabular}

IIRC, International Intraocular Retinoblastoma Classification; IMD, Index of Multiple Deprivation.

between Indian/Pakistani/Bangladeshi ethnicity, being in the lowest (most deprived) IMD quintile and presentation with advanced disease did not reach statistical significance.

Enhanced analysis of SES and Rb presentation (questionnaire results)

The response rate was $42 \%$ (79 responses out of 189). IIRC groups D or E were less likely to respond (39\% responded) compared with groups A-C $(53 \%$ responded); OR $0.57(0.28,1.20)$, which was not statistically significant.

Although there was a trend towards responding to the questionnaire with higher quantiles of IMD the results were not statistically significant $(\mathrm{p}=0.06)$. With regard to ethnicity, compared with English/Scottish/Welsh, mixed race participants were more likely to respond (OR $6.36(1.33,30), \mathrm{p}=0.021)$. A summary of the questionnaire responses is presented in table 3. There was no statistically significant association between language, employment status, social class, parental qualifications and accommodation tenure and outcomes (enucleation rate and adjuvant chemotherapy). Of note, there was no statistically significant association between the factors listed in table 3 and advanced disease (IIRC groups D and $\mathrm{E}$ ).

\section{DISCUSSION}

In this national study of patients with non-familial $\mathrm{Rb}$ diagnosed over a 6-year period to 2011 in the UK, there 
Table 2 Associations between advanced presentation of retinoblastoma (IIRC grades D and E) and treatment, and demographic and socioeconomic factors (by ORs). $n=189$

\begin{tabular}{|c|c|c|c|c|c|c|}
\hline & \multicolumn{2}{|c|}{$\begin{array}{l}\text { Advanced IIRC grade } \\
\mathrm{n}=153 / 189(81 \%)\end{array}$} & \multicolumn{2}{|c|}{$\begin{array}{l}\text { Enucleation }^{\star} \\
\mathrm{n}=134 / 189(71 \%)\end{array}$} & \multicolumn{2}{|c|}{$\begin{array}{l}\text { Adjuvant chemotherapy* } \\
n=68 / 134(50 \%)\end{array}$} \\
\hline & $\begin{array}{l}\text { Unadjusted } \\
\text { OR }\end{array}$ & Adjusted OR & $\begin{array}{l}\text { Unadjusted } \\
\text { OR }\end{array}$ & Adjusted OR & $\begin{array}{l}\text { Unadjusted } \\
\text { OR }\end{array}$ & Adjusted OR \\
\hline \multicolumn{7}{|l|}{ Gender } \\
\hline Female & 1 & & 1 & 1 & 1 & 1 \\
\hline Male & 1.10 & $1.03(0.46,2.30)$ & 1.01 & $1.04(0.47,2.30)$ & 0.68 & $0.50(0.22,1.17)$ \\
\hline \multicolumn{7}{|l|}{ Ethnicity } \\
\hline English/Scottish/Welsh & 1 & 1 & 1 & 1 & 1 & 1 \\
\hline $\begin{array}{l}\text { Indian/Pakistani/ } \\
\text { Bangladeshi }\end{array}$ & 2.86 & $3.13(0.62,16)$ & 1.86 & $1.40(0.36,5.41)$ & 0.75 & $0.75(0.22,2.59)$ \\
\hline $\begin{array}{l}\text { Black } \\
\text { Caribbean/African }\end{array}$ & 0.82 & $0.59(0.09,3.72)$ & 0.41 & $0.16(0.02,1.18)$ & 0.28 & $0.35(0.03,4.20)$ \\
\hline Mixed/other white or other & 2.05 & $3.92(0.77,20)$ & 1.34 & $0.93(0.23,3.76)$ & 0.37 & $0.37(0.09,1.56)$ \\
\hline \multicolumn{7}{|c|}{ IMD score (quintiles) } \\
\hline 1 (most deprived) & 1 & 1 & 1 & 1 & 1 & 1 \\
\hline 2 & 0.57 & $0.61(0.17,2.15)$ & 1.19 & $1.90(0.59,6.17)$ & 1.13 & $0.94(0.28,3.14)$ \\
\hline 3 & 0.39 & $0.35(0.09,1.37)$ & 1.11 & $2.55(0.63,10)$ & 1.22 & $1.03(0.25,4.28)$ \\
\hline 4 & 0.82 & $0.79(0.19,3.39)$ & 1.59 & $1.99(0.54,7.37)$ & 0.92 & $0.55(0.15,2.04)$ \\
\hline 5 (least deprived) & 0.55 & $0.57(0.16,2.07)$ & 0.99 & $1.19(0.36,3.94)$ & 0.81 & $0.66(0.20,2.25)$ \\
\hline \multicolumn{7}{|l|}{ Age at diagnosis } \\
\hline$<1$ year & 1 & 1 & 1 & 1 & 1 & 1 \\
\hline 1 to $<2$ years & 1.16 & $1.58(0.59,4.25)$ & 1.62 & $1.39(0.52,3.74)$ & 0.52 & $0.66(0.19,2.25)$ \\
\hline 2 to $<3$ years & 3.53 & $6.24(1.50,26)$ & 5.12 & $3.58(0.96,13)$ & 0.29 & $0.66(0.19,2.30)$ \\
\hline 3 to 12 years & 4.5 & $9.57(2.34,39)$ & 6.22 & $4.30(1.06,17)$ & 0.41 & $1.01(0.31,3.27)$ \\
\hline \multicolumn{7}{|l|}{ Laterality } \\
\hline Unilateral & 1 & 1 & 1 & 1 & 1 & 1 \\
\hline Bilateral & 1.46 & $3.24(1.23,8.57)$ & 0.52 & $0.48(0.19,1.20)$ & 15 & $16(4.8,56)$ \\
\hline
\end{tabular}

Models adjusted for all factors in the table.

Blod values are statistically significant as $95 \%$ confidence interval of odds ratio does not include 1 .

*Additional adjustment for IIRC groups.

IIRC, International Intraocular Retinoblastoma Classification; IMD, Index of Multiple Deprivation.

was no evidence of an association of ethnicity or SES and the risk of presenting with advanced disease.

A key strength of our study is that data were extracted from a prospective $\mathrm{Rb}$ database with no selection bias. In addition, we collected information on SES directly from the patients' parents to increase granularity of the data. For example, education is different from income and might help us with further interventions.

Also, during this period of data collection enucleation rates were over $70 \%$ and we had information regarding high-risk histopathological features. As globe salvage has increased due to new treatments (intra-arterial chemotherapy and intravitreal chemotherapy) such information is more difficult to acquire. However, the number of eyes that fall in the more advanced groups $\mathrm{D}$ and $\mathrm{E}$ remains valid parameters to study.

In the USA, it has recently been shown that there was a trend for Hispanics and those with unfavourable socioeconomic factors to have more advanced disease at presentation (more high-risk adverse histopathology on local review). However, central review of histopathology slides did not provide evidence that this was statistically significant. ${ }^{11}$ This suggests that there may have been bias at local review particularly if the name of the child was not masked from the histopathologist. From 2000 to 2010, the data from 830 children were analysed and an association between requirement for enucleation and being Hispanic and/or low SES existed. ${ }^{15}$ A retrospective analysis of the presentation of disease according to IIRC (particularly groups $\mathrm{D}$ and $\mathrm{E}$ ) may have been difficult to perform and the decision to enucleate was not standardised according to classification, thus bias on the part of the surgeon may have played a part. In addition, statistical significance was noted in mortality: 2 of 262 white children died (99\% 5-year survival) compared with 6 of 89 black children (93\% 5-year survival). The causes of 
Table 3 Distribution of household sociodemographic factors in a subsample with enhanced individual-level data on SES, by IIRC grade, enucleation and adjuvant chemotherapy

\begin{tabular}{|c|c|c|c|c|}
\hline & $\mathrm{n}$ & $\% \mathrm{D}$ or E IIRC grade & $\%$ enucleation & $\%$ adjuvant chemotherapy \\
\hline \multicolumn{5}{|l|}{ Language spoken } \\
\hline English only & 63 & 73.0 & 69.4 & 41.9 \\
\hline English and other language & 15 & 86.7 & 66.7 & 36.4 \\
\hline \multirow[t]{2}{*}{ No English } & 1 & 100 & 100 & 0 \\
\hline & & $p=0.46$ & $p=0.78$ & $p=0.67$ \\
\hline \multicolumn{5}{|l|}{ Employment status* } \\
\hline Student/unemployed & 5 & 100 & 80.0 & 75 \\
\hline \multirow[t]{2}{*}{ Employed } & 74 & 74.3 & 68.5 & 37.3 \\
\hline & & $p=0.94$ & $p=0.59$ & $p=0.14$ \\
\hline \multicolumn{5}{|l|}{ Social class status* } \\
\hline Professional & 22 & 90.9 & 72.7 & 43.8 \\
\hline Skilled & 28 & 60.7 & 64.3 & 42.1 \\
\hline Semiskilled & 11 & 81.8 & 72.7 & 25.0 \\
\hline \multirow[t]{2}{*}{ Manual } & 9 & 77.8 & 75.0 & 33.0 \\
\hline & & $p=0.09$ & $p=0.89$ & $p=0.81$ \\
\hline \multicolumn{5}{|c|}{ Highest qualification of main carer } \\
\hline None & 8 & 87.5 & 75.0 & 33.3 \\
\hline O level† & 23 & 65.2 & 54.6 & 41.7 \\
\hline A levelf & 16 & 68.8 & 81.3 & 30.8 \\
\hline \multirow[t]{2}{*}{ Degree } & 32 & 84.4 & 71.9 & 45.8 \\
\hline & & $\mathrm{p}=0.29$ & $\mathrm{p}=0.32$ & $\mathrm{p}=0.82$ \\
\hline \multicolumn{5}{|l|}{ Accommodation tenure } \\
\hline Home owner & 59 & 76.3 & 65.5 & 46.2 \\
\hline \multirow[t]{2}{*}{ Rental accommodation } & 20 & 75.0 & 80.0 & 25.0 \\
\hline & & $\mathrm{p}=0.91$ & $p=0.23$ & $p=0.15$ \\
\hline
\end{tabular}

*Main wage earner.

†State examination at age 16.

$\ddagger$ State examination at age 18 .

IIRC, International Intraocular Retinoblastoma Classification; SES, socioeconomic status.

mortality from $\mathrm{Rb}$ are again complex ranging from associated pinealoblastoma to treatment strategies and poor follow-up. Unfortunately, such details were not provided in that study. From 2000 to 2014, it was found that more patients from low SES and Hispanic patients were enucleated in the USA. ${ }^{16}$ However, there was no difference in the advanced nature of disease. This reflects variation in treatment approaches between centres in America and probably cost implications where it is cheaper to perform an enucleation than undergo other treatments. We present a study from the UK where there are only two centres and no cost implications to families. It is reassuring that no statistical difference was noted in enucleation rate for low SES and non-white patients.

Human Development Index for different countries correlates with survival for Rb. ${ }^{17}$ In Mexico, lower maternal education and poor prenatal housing conditions were significantly predictive of overall survival in unilateral disease, and more advanced IIRC grouping in bilateral disease, independent of diagnostic delay. ${ }^{18}$ In Brazil, maternal education carried a significant difference with outcomes (advanced stage at diagnosis, enucleation and survival). ${ }^{19}$ Interestingly, low SES per se was not associated with poorer outcomes.

We have previously shown that in the UK high-risk $\mathrm{Rb}$ (requiring adjuvant chemotherapy) is not associated with delayed lag time (time to diagnosis). ${ }^{9}$ This is counterintuitive but is found in all other paediatric cancers in high-resource countries. ${ }^{20}$ Whereas low SES may be associated with more advanced disease at presentation in low-resource countries or countries with unequal healthcare access, we wanted to understand if there were any vulnerable groups in a healthcare system that was free at point of access such as the UK. We have found no evidence of an association to suggest SES or a certain ethnic group is disadvantaged. It is also difficult to argue that any particular ethnic group (present in the UK) is biologically more susceptible to advanced disease. 
Our study draws on a national sample representative of the UK population of children with non-familial Rb. Nevertheless, power to detect true differences in risk of presentation with advanced disease may have been limited by the size of the sample. An inherent limitation to studying $\mathrm{Rb}$ is the rarity of the disease. As we hypothesised that ethnicity and SES may be risk factors, we undertook primary data collection on person/individuallevel SES factors, in order to allow deeper understanding of pathways. Unfortunately, we had only a moderate response to the questionnaire survey which limited our sample size further. There were some differences that failed to reach statistical significance. For example, there was some indication that Indian/Pakistani/Bangladeshi ethnicity, and being in the lowest IMD quintile were associated with higher likelihood of D/E IIRC grade, but this was not statistically significant. This may be due to the small study population size leading to inadequate power. However, the results are similar to the findings of another high-resource country (USA) that has looked at this study question. $^{11}$

In summary, we report the largest cohort of patients with $\mathrm{Rb}$ in the UK with prospective data on ethnicity and SES. Although there is a trend between low SES and certain ethnic groups with advanced $\mathrm{Rb}$, we have found no evidence of an association. This may reflect equality in access in primary healthcare. As a result, awareness campaigns highlighting the white reflex and strabismus should continue in their present format.

\section{Author affiliations}

${ }^{1}$ Moorfields Eye Hospital NHS Foundation Trust, London, UK

${ }^{2}$ Ulverscroft Vision Research Group, Great Ormond Street Institute of Child Health, UCL, London, UK

${ }^{3}$ Ocular Oncology Service, Goldschleger Eye Institute, Sheba Medical Centre, TelAviv University, Tel Aviv, Israel

${ }^{4}$ NIHR Biomedical Research Centre, Moorfields Eye Hospital and University College London Institute of Ophthalmology, London, UK

${ }^{5}$ Department of Paediatric Ophthalmology, Birmingham Children's Hospital,

Birmingham, UK

${ }^{6}$ Ophthalmology, Barts Health NHS Trust, London, UK

${ }^{7}$ Paediatric Ophthalmology, Great Ormond Street Institute of Child Health, University College London, London, UK

Contributors RB, MAR, PC, MP JR and MSS planned the study. RB and HA collected the data and conducted the questionnaires. PC, RB and IDF analysed the results. $\mathrm{RB}$ wrote the paper, and all the authors modified the manuscript and agreed on submission. RB submitted the manuscript.

Funding Research grant from the Royal National Institute of the Blind, UK. PC was funded by the Ulverscroft Foundation.

Disclaimer The views expressed in this article are those of the authors and not necessarily those of the NHS, the NIHR or the Department of Health. The funding organisation had no role in the design or conduct of this research.

Competing interests None declared.

Patient and public involvement Patients and/or the public were not involved in the design, or conduct, or reporting, or dissemination plans of this research.

Patient consent for publication Not required.

Ethics approval The study was approved by the National Research Ethics Committee (Reference 11/L0/0981).

Provenance and peer review Not commissioned; externally peer reviewed.
Data availability statement Data are available upon request.

Open access This is an open access article distributed in accordance with the Creative Commons Attribution Non Commercial (CC BY-NC 4.0) license, which permits others to distribute, remix, adapt, build upon this work non-commercially, and license their derivative works on different terms, provided the original work is properly cited, appropriate credit is given, any changes made indicated, and the use is non-commercial. See: http://creativecommons.org/licenses/by-nc/4.0/.

ORCID ID

Rabia Bourkiza http://orcid.org/0000-0001-9101-9863

\section{REFERENCES}

1 Kivelä T. The epidemiological challenge of the most frequent eye cancer: retinoblastoma, an issue of birth and death. $\mathrm{Br} J$ Ophthalmol 2009;93:1129-31.

2 Linn Murphree A, Murphree AL. Intraocular retinoblastoma: the case for a new group classification. Ophthalmol Clin North Am 2005; 18:41-53.

3 Shields CL, Mashayekhi A, Au AK, et al. The International classification of retinoblastoma predicts chemoreduction success. Ophthalmology 2006:113:2276-80

4 Fabian ID, Stacey AW, Johnson KP, et al. Primary intravenous chemotherapy for group $D$ retinoblastoma: a 13-year retrospective analysis. Br J Ophthalmol 2017;101:82-8.

5 Kaliki S, Srinivasan V, Gupta A, et al. Clinical features predictive of high-risk retinoblastoma in 403 Asian Indian patients: a case-control study. Ophthalmology 2015;122:1165-72.

6 Honavar SG, Singh AD, Shields CL, et al. Postenucleation adjuvant therapy in high-risk retinoblastoma. Arch Ophthalmol 2002;120:923-31.

7 Leander C, Fu LC, Peña A, et al. Impact of an education program on late diagnosis of retinoblastoma in Honduras. Pediatr Blood Cancer 2007;49:817-9

8 Ribeiro KdeCB, Antoneli CBG. Trends in eye cancer mortality among children in Brazil, 1980-2002. Pediatr Blood Cancer 2007;48:296-305.

9 Posner M, Jaulim A, Vasalaki M, et al. Lag time for retinoblastoma in the UK revisited: a retrospective analysis. BMJ Open 2017;7:7.

10 Chawla B, Kumar K, Singh AD. Influence of socioeconomic and cultural factors on retinoblastoma management. Asia Pac J Oncol Nurs 2017;4:187-90.

11 Green AL, Chintagumpala M, Krailo M, et al. Correlation of insurance, race, and ethnicity with pathologic risk in a controlled retinoblastoma cohort: a children's Oncology Group study. Ophthalmology 2016;123:1817-23.

12 UK Government website, 2019. Available: https://www.gov.uk/ government/collections/english-indices-of-deprivation [Accessed on 3 February].

13 Office of National Statistics. Standard occupational classification 2000. Available: https://www.ons.gov.uk/methodology/classificati onsandstandards/standardoccupationalclassificationsoc [Accessed on 3 February 2019].

14 Kaliki S, Shields CL, Shah SU, et al. Postenucleation adjuvant chemotherapy with vincristine, etoposide, and carboplatin for the treatment of high-risk retinoblastoma. Arch Ophthalmol 2011:129:1422-7.

15 Truong B, Green AL, Friedrich P, et al. Ethnic, racial, and socioeconomic disparities in retinoblastoma. JAMA Pediatr 2015:169:1096-104.

16 Rajeshuni N, Whittemore AS, Ludwig CA, et al. Racial, Ethnic, and Socioeconomic Disparities in Retinoblastoma Enucleation: A Population-Based Study, SEER 18 2000-2014. Am J Ophthalmol 2019;207:215-23.

17 Canturk S, Qaddoumi I, Khetan V, et al. Survival of retinoblastoma in less-developed countries impact of socioeconomic and healthrelated indicators. Br J Ophthalmol 2010;94:1432-6.

18 Ramírez-Ortiz MA, Ponce-Castañeda MV, Cabrera-Muñoz ML, et al. Diagnostic delay and sociodemographic predictors of stage at diagnosis and mortality in unilateral and bilateral retinoblastoma. Cancer Epidemiol Biomarkers Prev 2014:23:784-92.

19 Mattosinho CCdeS, Grigorovski N, Lucena E, et al. Prediagnostic intervals in retinoblastoma: experience at an oncology center in Brazil. J Glob Oncol 2017;3:323-30.

20 Barr RD. "Delays" in diagnosis: a misleading concept, yet providing opportunities for advancing clinical care. J Pediatr Hematol Oncol 2014;36:169-72. 